arthritis patients and allow an earlier decision to start proper medication and defining progression or remission of the disease.

\section{THU0180 IDENTIFYING RAPID RADIOGRAPHIC PROGRESSORS IN RHEUMATOID ARTHRITIS}

${ }^{1} \mathrm{JB}$ Wong, ${ }^{2} \mathrm{CJ}$ Wong, ${ }^{3} \mathrm{PL}$ Van Riel, ${ }^{4} \mathrm{JM}$ Hazes, ${ }^{5} \mathrm{FC}$ Breedveld, ${ }^{6} \mathrm{DM}$ Van der Heijde, ${ }^{2}$ BG Feagan. 'Medicine - Clinical Decision Making, Tufts - New England Medical Center, Boston, USA; 'London Clinical Trials Research Group, Robarts Research Institute, London, Canada; ${ }^{3}$ Rheumatology, University Hospital, Nijmegen; ${ }^{4}$ Rheumatology, University Hospital, Rotterdam; ${ }^{5}$ Rheumatology, Leiden University Medical Center, Leiden; ${ }^{6}$ Rheumatology, University Hospital, Maastricht, Netherlands

10.1136/annrheumdis-2001.1082

Background Mounting evidence suggests that radiographically progressive disease identifies rheumatoid arthritis patients at higher risk for developing future disability. Hand and foot radiographs, however, incur additional expense and have not become a part of routine practice.

Objectives To determine if clinical parameters can be used to identify patients with radiographic progression.

Methods In 2 Dutch cohorts of early rheumatoid arthritis patients from Leiden and Nijmegen, 279 patients had year 2 or 3 radiographs (mean age 50.5 years, $76.7 \%$ women, $71.7 \%$ RF ,$+ 60.1 \%$ HLA DR4+). Using the OMERACT definition, radiographic progression was defined as exceeding the smallest detectable difference (SDD) or 15 modified Sharp units. Because xrays were done after 2 or 3 years from RA onset, we used the annual radiographic progression rate to define progressors (>7.5) vs non-progressors (

Results In this cohort, 199 of the 279 patients (71\%) were radiographic ?progressors? after $2-3$ years of RA. Univariate analysis showed that older age, $\mathrm{RF}+$, higher Disease Activity Score (DAS) and Ritchie articular index (all p < 0.03) were associated with radiographic progression. In the multivariate model, RF positivity (OR 4.78, CI $2.32-9.86$ ), older age (OR 1.75 per 10 years, CI 1.36 - 2.27) and higher DAS (OR 1.88, CI $1.32-$ 2.69) remained significant. The area under the ROC was 0.81 . The resulting sensitivity (SEN) and specificity (SP) values using the following cutpoints were (cutpoint $=$ SEN/SP): $0.50=94 /$ $48,0.60=89 / 60,0.70=81 / 68,0.80=64 / 79$. Thus, treating all patients with predicted probabilities above 0.50 would miss $6 \%$ of the radiologic progressors and result in treatment of $52 \%$ of the non-progressors. Or treating only patients with predicted probabilities above 0.80 would miss $36 \%$ of the progressors and treat $21 \%$ of the non-progressors.

Conclusion Non-radiographic clinical parameters do not adequately identify rheumatoid arthritis patients with radiographically progressive joint disease. Performing routine $\mathrm{x}$-rays to target new RA treatments that stabilise radiologic joint disease toward radiologic progressors is likely to yield the most favourable cost-effectiveness ratios.

\section{THU0181 CLINICAL RESULTS OF AN OPEN LABELLED EVALUATION OF THE TREATMENT WITH INFLIXIMAB IN THERAPY RESISTANT RHEUMATOID ARTHRITIS}

M Spak, E Cauza, U Hanusch, G Haberhauer, A Dunky. Department of Rheumatology, 5. Med., Wilhelminen Spital, Vienna, Austria
Background Evaluation of the efficacy and safety of the chimeric anti tumour nekrosis factor alpha (TNFa) antibody Infliximab in therapy resistant rheumatoid arthritis (RA).

Objectives

Methods 22 patients (mean age 59 years, mean duration of disease 9,5 years) with active RA, according to the ACR criteria, which were therapy resistant to two and more disease modifying antirheumatic drugs (DMARDs), including MTX, received 3 infusions of $3 \mathrm{mg} / \mathrm{kg}$ Infliximab at week 0,2 and 6 . Nine patients have been observed over a period of 30 weeks $(0,2,6$, 14, 22, 30). Standard clinical and laboratory assessments, including swollen joint count (SJC), tender joint count (TJC), morning stiffness (MST), visual analogue scale of patient pain assessment (VAS), C- reactive protein (CRP) and erythrocyte sedimentation rate (ESR) were evaluated at baseline and at any time of drug administration.

Results After 3 infusions 65\% of the patients achieved an $20 \%$ response (ACR 20). All clinical and laboratory assessments showed a significant improvement [SJC 10,2 before (B) vs.3,2 after 3 infusions (A), $\mathrm{p}=0,001$, TJC 26,6 (B) vs.9,1 (A), $\mathrm{p}=$ 0,001, MST 101,2 $\min (\mathrm{B})$ vs. $36,8 \mathrm{~min}(\mathrm{~A}), \mathrm{p}=0,002$, CRP $26,9 \mathrm{mg} / \mathrm{dl}(\mathrm{B})$ vs. $17 \mathrm{mg} / \mathrm{dl}(\mathrm{A}), \mathrm{p}=0,015$, ESR 56,6 mm (B) vs. $31,2 \mathrm{~mm}(\mathrm{~A}), \mathrm{p}=0,001$, VAS 7,4 (B) vs. 4,1 (A)]. Only mild adverse events but no severe infections occurred in the observation period.

After 30 weeks 44\% maintained an ACR 20 response. A sustained improvement of clinical and laboratory assessments was observed.

Conclusion Infliximab seems to be an effective and safe treatment of therapy resistant active RA with a sustained improvement in clinical and laboratory assessments over a period of 30 weeks.

\section{THU0182 SIGNIFICANT REDUCTION IN SERIOUS UPPER GASTROINTESTINAL (UGI) EVENTS WITH CELECOXIB, A COX-2 SPECIFIC INHIBITOR, COMPARED WITH CONVENTIONAL NSAIDS. THE SUCCESS I TRIAL}

${ }^{1} \mathrm{JL}$ Goldstein, ${ }^{2} \mathrm{G}$ Eisen, ${ }^{3} \mathrm{~W}$ Stenson, ${ }^{4} \mathrm{~N}$ Agrawal, ${ }^{5} \mathrm{AE}$ Bello, ${ }^{5} \mathrm{JG}$ Fort, ${ }^{5} \mathrm{SP}$ Boots. ${ }^{1}$ Department of Medicine, University of Illinois at Chicago, Chicago; ${ }^{2}$ Department of Medicine, Vanderbilt University Medical Center, Nashville; ${ }^{3}$ Department of Medicine, Washington University Medical School, St Louis; ${ }^{4}$ Department of Medicine, Duke University Medical Center, Durham; ${ }^{5}$ Research and Development, Pharmacia Corporation, Skokie, USA

\subsection{6/annrheumdis-2001.1084}

Background The Celecoxib Long-term Arthritis Safety Study (CLASS), a North American prospective outcomes study, demonstrated a significant reduction in UGI ulcer complications and improved tolerability.

Objectives To extend our understanding of the UGI safety advantages of celecoxib over conventional NSAIDs, a naturalistic study was conducted worldwide.

Methods SUCCESS I, a large, 12-week, multinational, prospective, double-blind, randomised trial in 13,274 osteoarthritis patients, was conducted in 39 countries. There were 6547 patients from Europe/Africa, 2756 from North America, 2889 from Latin America, and 1082 from Asia/Pacific. Celecoxib 200 $\mathrm{mg} / \mathrm{d}(\mathrm{n}=4421)$ and $400 \mathrm{mg} / \mathrm{d}(\mathrm{n}=4429)$ was compared with naproxen $1000 \mathrm{mg} / \mathrm{d}(\mathrm{n}=914)$ and diclofenac $100 \mathrm{mg} / \mathrm{d}(\mathrm{n}=$ 3510) with regard to UGI safety. Investigators were required to report all potential clinically significant UGI events and were allowed/requested to follow local standards of care with regard to work-up and treatment of events. Events data were collected 